\title{
Niobium (V) Chloride Catalyzed Abramov Reaction: An Efficient Protocol for the Preparation of $\alpha$-Hydroxy Phosphonates
}

\author{
Venugopal Thottempudi and Kyoo-Hyun Chung* \\ Department of Chemistry and High Energy Haterial Research Center, Inha Cniversitv, Incheon 402-751, Korea \\ E-mail: hoohwnicinhacackr \\ Received April 8, 2008
}

Key Words : Abramov reaction $\alpha$-Hydroxy phosphonates. $\mathrm{NbCl}_{s,}$ Solvent-free

The syntheses of $\alpha$-hydroxy phosphonates have received an increasing amount of attention due to significant biological interests. They showed potential biological activities. such as antiviral. antibacterial. anticancer. pesticides. renin inhibitors, HIV protease. and enzyme inhibitor properties. ${ }^{3}$ Much of these activities has been attributed to the relatively inert nature of the C.P bond and to the physical and structural sinilarity of phosphonic and phosphinic acids to the biologically important phosphate ester and carboxylic acid functionality. ${ }^{2}$ In addition. $\alpha$-hydroxy phosphonates are useful precursors for the preparation of $\alpha$-functionalized phosphonates, such as amino, keto. halo, and acetoxy phosphonates. $^{3}$

$\alpha$-Hydroxy phosphonates were usually prepared in the reaction of aldehydes or ketones with dialkyl or trialkyl phosphites in the presence of catalysts.

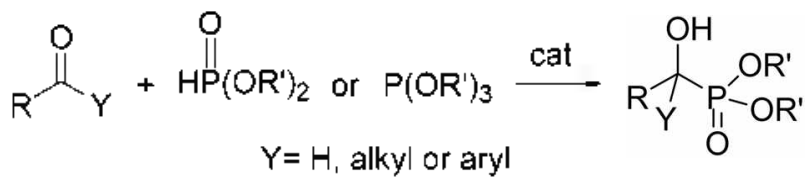

With dialkyl phosplites (dialkyl phosphonites), many reactions have been successfully performed in the presence of alumina, potassium fluoride on alumina, cesium fluorides. quarternary ammonium hydroxide ion exchange resin, RAl(salen) complex, L-prolinamide. and titanium alkoxides. ${ }^{+}$ With trialkyl phosphites, lithium perchlorate in diethyl ether. guanidine hydrochloride, etheral hydrogen chloride. and Amberlyst-15 were used as catalyslts. "Tris(trimethylsilyl) phosphite was also employed at higher temperature under anlydrous reaction conditions. ${ }^{6}$

These methods often met some disadvantages of difficult conditions such as high reaction temperature. longer reaction time and dried conditions. Moreover. the yields were not always good and sometimes byproducts were obtained, and esters of $\alpha$-hydroxy alkyl phosphonic acid were often cleaved to regenerate the starting carbonyl compounds when strong alkaline mediunts were used. ${ }^{7}$

Although trialkyl phosphites are much better nucleophiles than dialkyl phosphites. because of their free electron pairs on the phosphorus atom, ${ }^{5 \mathrm{l}}$ a few reports described the reaction of trialkyl phosphite with aldehydes or ketones. Hence, there is a need to develop a convenient. envirommentally benign. and feasible method for the synthesis of $\alpha$-hydrosy phosphonates using trialkyl phosphites.

Recently, $\mathrm{NbCl}_{\text {s }}$ has emerged as an efficient Lewis acid in promoting various organic transformations, such as DielsAlder reaction. ring-opening of epoxides, Mukaiyama aldol reaction. Biginelli reaction. dealky lation of alkyl aryl ethers, $\mathrm{C}-\mathrm{H}$ insertion, and cyanosilylation. "The versatility of this reagent has encouraged us to study its possibility for the synthesis of $\alpha$-lyydrosy phosphonates.

Herein. we report solvent free synthesis of $\alpha$-hydrosy phosphonates in the reactions of carbonyl compounds and tialkyl phosphite in the presence of $\mathrm{NbCl}_{5}$ at room temperature.

Our initial experiments focused on the optimization of the amount of $\mathrm{NbCl}_{5}$ in the reaction of benzaldehyde with triethyl phosphite. Without trimethylsilyl chloride (TMSCl), increment of $\mathrm{NbCl}_{5}$ showed no substantial improvement in the yield. As shown in Table 1 , the reaction completed within $20 \mathrm{~min}$ in $94 \%$ yield (entry 1 in Table 1 ). in the presence of 1 equiv of TMSCl as an additive. When the reaction was carried out only either with $\mathrm{TMSCl}$ or with $\mathrm{NbCl}_{5}$, the reaction proceeded very slowly, and in poor yields (less than $50 \%$ ) even in $6 \mathrm{~h}$. We also observed that 5 mol $\%$ of $\mathrm{NbCl}_{s}$ could effectively catalyze the reaction. Since the yield was less than $60 \%$ by using solvents such as

Table 1. Reactions of benzaldehyde with triethyl phosphite in the presence of $\mathrm{NbCl}_{5}$ and/or TMSCla

\begin{tabular}{ccccc}
\hline Entry & Time & NbCl $_{5}$ & TMSCl & NbCl $_{5}$ and TMSCl \\
\hline 1 & $20 \mathrm{~min}$ & 25 & 15 & 94 \\
2 & $1 \mathrm{~h}$ & 37 & 23 & 94 \\
3 & $3 \mathrm{~h}$ & 54 & 38 & 94 \\
4 & $6 \mathrm{~h}$ & 59 & 47 & 94 \\
\hline
\end{tabular}

AAll vields refer to isolated products. 0.05 equiv. of $\mathrm{NbCl}$ and or 1.0 equiv of TMSCl were used. 


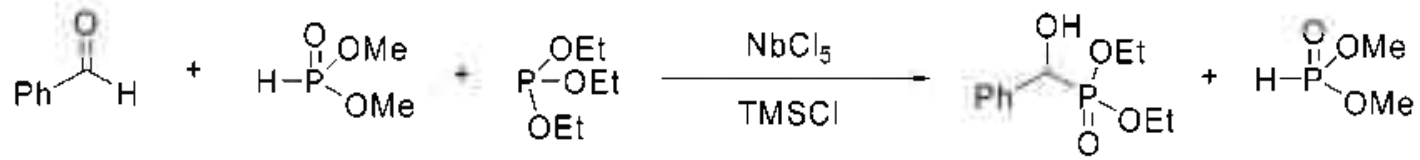

Scheme 1. Competitive Abramov reaction of dialkyl and trialkyl phosphites.

Table 2. Synthesis of $\alpha$-hydroxyphosphonates from various aldehydes"

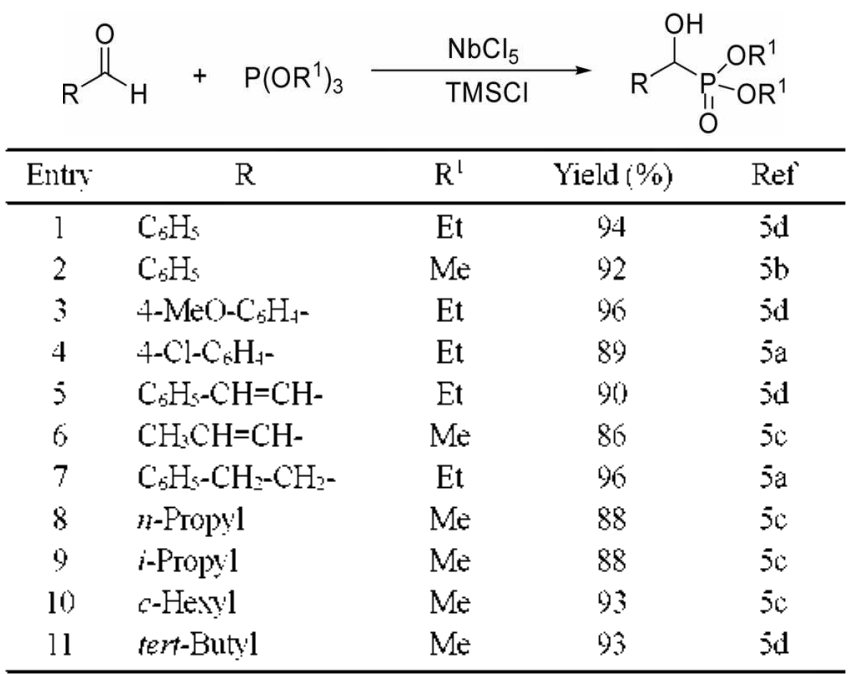

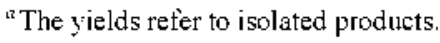

$\mathrm{CH}_{2} \mathrm{Cl}_{2}, \mathrm{MeOH}$. THF and $\mathrm{MeCN}$. the further reaction was carried out under sovent-free conditions.

As listed in the Table 2, all the reactions of aldehydes readily proceeded to afford the corresponding $\alpha$-hydroxy phosphonates in high yields within 20 min. The reactions were hardly affected by steric hindrance. $\alpha, \beta$-Unsaturated aldelyydes also selectively gave the corresponding $\alpha$-hydroxy phosphonates in good yield, without any by-products (entries 5 and 6 in Table 2 ).

Next. we examined the scope and limitation of the reaction of some ketones under similar reaction conditions. As shown in Table 3, the reaction time $(60-90 \mathrm{~min})$ and yields were comparable with the previous results. ${ }^{57 \mathrm{~b}}$ Aliphatic ketones proceeded better than aromatic ketones. The reaction of 2-butanone with triethyl phosphite gave diethyl 1-hyddroxy-1-methy lpropylphosphonate in $84 \%$ yield (entry 1 in Table 3). When the reaction of cyclohexanone with trimethỵl phosphite or triethyl phosphite was carried out the corresponding phosphate was afforded in about $60 \%$ yield (entries 2 and 3 in Table 3 ). However the reaction was quite sensitive to steric hindrance. resulting that acetophenone reacted slowly and benzophenone did not.

A cross experiment was perfomed to confinm the competition on the reactivity of alkỵl phosphites. by mixing stoichiometric amounts of benzaldehyde triethyl phosphite and dimethyl phosphite under the same reaction conditions. Only triethyl phosphite reacted to give diethyl 1-hydroxy-lphenylmethylphosphonate in $94 \%$ yield as expected ${ }^{\text {id }}$

To investigate the nucleophile of the reaction, we carried out a control experiment of equimolar mixture of triethyl
Table 3. Synthesis of $\alpha$-hydroxyl phosphonates from some ketones"

\begin{tabular}{|c|c|c|c|c|c|}
\hline \multirow[b]{2}{*}{ Entry } & \multicolumn{2}{|c|}{$+\mathrm{P}\left(\mathrm{OR}^{2}\right)_{3}$} & \multirow{2}{*}{$\begin{array}{c}\frac{\mathrm{NbCl}_{5}}{\mathrm{TMSCl}} \\
\mathrm{R}^{2}\end{array}$} & \multicolumn{2}{|c|}{$\mathrm{R}_{\mathrm{R}^{1}}^{\mathrm{O}} \mathrm{OR}_{\mathrm{O}}^{\mathrm{O}} \mathrm{OR}^{2}$} \\
\hline & $\mathrm{R}$ & $\mathrm{R}^{\mathrm{l}}$ & & Yield (\%) & Ref \\
\hline 1 & $\mathrm{Et}$ & $\mathrm{Me}$ & $\mathrm{Et}$ & 84 & $7 \mathrm{~b}$ \\
\hline 2 & $-\left(\mathrm{CH}_{2}\right)_{5-}$ & - & $\mathrm{Me}$ & 65 & $5 a$ \\
\hline 3 & $-\left(\mathrm{CH}_{2}\right)_{s-}$ & - & $\mathrm{Et}$ & 59 & 51 \\
\hline 4 & $\mathrm{C}_{\alpha} \mathrm{H}_{s}$ & $\mathrm{Me}$ & $\mathrm{Et}$ & 44 & 51 \\
\hline 5 & $\mathrm{C}_{\alpha} \mathrm{H}_{5}$ & $\mathrm{C}_{\alpha} \mathrm{H}_{\xi}$ & $\mathrm{Et}$ & - & - \\
\hline
\end{tabular}

a.l yields refer to isolated products. The reaction was taken place for 60 to $90 \mathrm{~min}$.

phosphite and TMSCl in the presence of catalytic amounts of $\mathrm{NbCl}_{5}(0.05 \mathrm{eqv})$ at $\mathrm{rt}$ for $2 \mathrm{~h}$, there was no evidence of the formation of silyl phosphite or any other reaction product on ${ }^{1} \mathrm{H}$ NMR. ${ }^{-}$Therefore, the nucleophile was not silyl phosphite. but trialkyl phosphite. ${ }^{56,5 d}$

In summary. we have developed a new protocol for the synthesis of $\alpha$-hydroxy phosphonates using catalytic amount of $\mathrm{NbCl}_{\text {s. }}$. The method is effective for a variety of aliphatic and aromatic carbonyl compounds. provides the product in high yield in a short reaction time without solvent. Experimental convenience. high yields, and clean reaction conditions make this method an attractive and useful protocol.

\section{Experimental Section}

Materials. All reagents were purchased from Aldrich Chemical Co. and used without further purification. All $\alpha$ hydroxy phosphonates mentioned in this paper were known. and their references were listed in Tables.

Typical procedure: To a mixture of benzaldehyde ( 5 mumol) and triethyl phosphite $(5 \mathrm{mmol})$, was added $\mathrm{NbCl}_{5}$ $(0.05 \mathrm{~mol} \%)$ and trimethylsilyl chloride (5 mmol). After stirring for $20 \mathrm{~min}$, the resulting mixture was extracted with dichloromethane $(15 \mathrm{~mL})$. The organic layer was washed with water $(15 \mathrm{~mL})$. sat. $\mathrm{NaHCO}_{3}$ solution $(15 \mathrm{~mL})$ and brine solution $\left(15 \mathrm{~mL}\right.$ ), dried over $\mathrm{MgSO}_{4}$ and concentrated in vacuo to give nearly pure diethyl 1-hydroxy-1-phenylmethylphosphonate $(94 \%)$ as a white solid. All spectral data were the same as reported in literature ${ }^{\text {ib. } .^{\mathrm{is}} \mathrm{mp}} 76.78^{\circ} \mathrm{C}$ (lit. 78-80); ${ }^{1} \mathrm{H}$ NMR $\left(\mathrm{CDCl}_{3}, 400 \mathrm{MHz}\right) \delta=1.12-1.21(\mathrm{~m}, 6 \mathrm{H}$, $\left.2 \mathrm{CH}_{3}\right), 3.94-4.13\left(\mathrm{~m} .4 \mathrm{H}, 2 \mathrm{CH}_{2}\right), 4.95$ (d. $J=12 \mathrm{~Hz} .1 \mathrm{H}$, $\mathrm{CH}$ ) 5.20 (br. $\mathrm{lH}, \mathrm{OH}$ ), 7.24-7.30 (m, 3H. Ar). 7.41-7.50 (m, 2H, Ar): ${ }^{12} \mathrm{C}$ NMR $\left(\mathrm{CDCl}_{3}, 100 \mathrm{MHz}\right) \delta=16.3 .63 .0$. 63.3 .70 .3 .126 .9 .127 .7 .127 .9 .136 .6 .

Acknowledgments. This work was supported by INHA UNIVERSITY Research Grant. 


\section{References and Notes}

1. (a) Kolodiazhnyi. O. J. Tetrahedron: Assmmetn 2005. 16. 3295. (b) Brenne. M. I.: Jaques, J.: Brianso, M. C.: Surcouf, E. Non, J. Chim. 21978 19. (c) Kim. D. Y: Wiemer. D. F. Tetahedion Lett. 2003, 4f, 2803. (d) Neyts. J; De Clereq. E. Antmicrob. Agents Chemother: 1997, 41.2754. (e) Fleisch. H. Endcor: Rev 1998. 19. 80. (t) Lee. M. V: Fong. E. M.: Singer. F. R.: Guenett. R. S. Cancer Res. 2001. 61. 2602. (g) Kafarski. P.: Lejczak. B. J. Mol. Catal. B: Enzym. 2004. 29, 99. (1) Patel. D. V: Rielly-Gauvin. K: Ryono, D. E.: Free. C. A.: Rogers. W. L.: Snith, S. A.; DeForrest, I. M. Oell1 R. S: Petrillo. E. W. Ir. J. Med Chem 1995. 38. 4557. (i) Stowasser. B.: Budt. K. H.: Jian-Di. L.: Peyman. A: Ruppert. D. Tetrohedron Lett. 1992. 33. 6625. (i) Hwang. J.-M.: Yeom. S.-H.: Jung. K.-Y. Bull, Korean Chen. Soc. 2007. 28. 821.

2. Fields, S. C. Tetrahedron 1999,55. 12237.

3. (a) Kaboudin. B. Tetrahedron Lett 2003 H. 1051. (b) Firouzabadi. H.: Iranpoor, N.: Sobhani. S. Symh. Commm. 2004. 34. 1463. (c) Iorga. B.: Eymery. F.: Savignac. P. Tetrohedron 1999, 55. 2671. (d) Firouzabadi. H.: Iranpoor. N.: Sobhani. S.: Amoozgar. Z. Sinthesis 2004. 1771.

4. (a) Texier-Boullet F: Foucaud, A. Symhesis 1982, 916. (b) Texier-Boullet. F; Lequitte. M. Tetrahedron Lett 1986. $27,3515$. (c) Alexander C. W. Albiniak. P. A.: Gibson. L. R. Phosphonus. Sulfur, and Silicon 2000. 167. 205. (d) Saito. B.: Egami. H.:
Katsuki. T. J. An. Chem. Soc. 2007. 129. 1978. (e) Dodda. R.: Zhao. C.-G. Ong Lent 2006. 8.4911. (f) Yokomatsu. T.: Yamagishi. T.: Shibuya. S. Tetrahtedron: Astmmtetry 1993. t. 1779.

5. (a) Azizi. N.: Saidi. M. R. Phosphorus. Sulfw and Silicon 2003. 178. 1255. (b) Hevdari. A.: Arefi, A.; Khaksar, S.; Tajbakihsh, M Catal. Conmun. 2006, 7, 982. (c) Tajbakshi, M; Heydari. A: Khalizadeh. M. A.: Lakouraj. M. M.: Zamenian. B.: Khaksar. S Smlet 2007. 15. 2347. (d) Goldeman. W.: Soroka. M. Smthesis 2006. 3019.

6. Evans, D. A.; Hurst. K. M.; Takacs, J. M. J. Am. Chem. Soc. 1978. 100. 3467

7. (a) Sum, V: Kee. T. P. J. Chem. Soc. Perhin Trans. I 1993. 2701. (b) Keglevich. G.: Sipos. M.: Takacs. D.: Greiner. I. Heterooton Chent 2007. 18. 226. (c) Gancalz. R.: Gancalz. I.: Walkkowiak. U. Phasphonis. Sulfur, and Silicon 1995. 104. 45.

8. (a) Kobayashi. S.: Busujima, T: Nagayama, S. Chem. Em: d. 2000. 6, 3491 . (b) Wang. R.: Li. B.-g.: Huang. T.-k.: Shi, L.: Lu. X.-X. Tetrahedron Lett. 2007, 48, 2071. (c) Andrade. C. K. Z: Azevedo. N. R.: Olivera. G. R. Tetrahedron Letf. 2001. 42.6473. (d) Andrade. C. K. Z.: Matos. R. A. F. Sinlett 2003. 1189. (e) Sudo. Y.: Arai. S.: Nishida. A. Eut J. Org. Chem. 2006. 3. 752. (f) Hernandez, H.: Bemes, S.: Quintero. L.: Sansinenea. E.: Ortiz, A. Tetrahedron Lett. 2006, 47, 1153. (g) Yadav. J. S.; Subba Reddy. B. V: Eeswaraiah, B.; Reddy. P. N. Tetrahedron 2005. 61, 875. (h) George. S. C.: Kim. S. S. Bull. Korean Chem. Soc. 2007. 28. 1167. 